\title{
NEW TYPE OF TRANSPORTATION ELECTRIC VEHICLES
}

\author{
Moustafa EL-Sayed EL-SHEBINY \\ Department of Electrical Engineering, Faculty of Engineering, \\ Shebin El-Kon, Egypt,
}

\begin{abstract}
An electric vehicle is one of the most promising technologies for the $21^{\text {st }}$ century, it is one of the solutions to energy problems in the future. For electric car propulsion, the wheel motor is an application that requires the electrical machines to have flexibility, compactness, robustness, high efficiency, and high torque. This paper describes an on-line control technique for ac drive system composed of two single phase induction motor to be employed in a special electric vehicle used in big factories to transport objects between places with radial or curvature trajectory. An experimental simulator of the proposed system is implemented. The simulation results agree with the experimental results.
\end{abstract}

\section{Introduction}

Various system of traction may encompass internal diesel combustion engine, and electric motor drive. Electrification is extensively developed in the last years, and is the most widely used system for rail road traction. In this system. The advantages for such a system are rapid acceleration and braking capabilities [1]. Electric traction technique is used in carrying heavy loads in high capacity factories. Electric drives have replaced hydraulic systems as the primary means of actuation and guided manipulation. Their applications are wide spread ranging from robots to automobiles [2]. A high performance drive system consists of motor, converter, and controller integrated to perform a precise mechanical maneuver $[3,6,7]$. This requires the shaft speed and or position of the motor to closely follow a specified trajectory. Axial flux machines are an interesting solution, where the motor is directly coupled to, or located inside, the drive wheels.

Manuscript received from Dr. M.EL-SHEBINY on : 20/2/2000

Accepted on : $6 / 6 / 2000$

Engineering Research Bulletín, Vol 23, No 3, 2000 Minufiya University, Faculty of Engineering, Shebien El-Kom, Egypt, ISSN 1110-1180 
The most important component in speed control is the electronic converter, which is placed between the supply and motor such as AC thyristor converter and Pulse-Width Modulated converters [4,9]. Also, the controller plays an important role in ac drive systems. The superiority of microprocessor control over conventional hardware control can easily be recognized for such a complex system. In addition to hardware simplification and reliability improvements, microprocessor implementation permits flexibility of control algorithms, which can be altered or expanded easily in the future [5]. In a conventional vehicle, controlling the motors will provide equal torque to the two driving wheels, independently of their speeds. this may also be achieved by controlling two individual motors $[4,7]$, but the expense of one set of drive electronics may be saved by using the two induction motors in series. The two-connected, series motors share the supply controlled voltage. Therefore, the motor with the lower slip takes more voltage than the other. This effect tends to compensate the lower slip and produces a more even sharing of torque between the two motors. An electric vehicle driven by two similar solid rotor induction motors [10] is proposed where two solid rotor induction motors are connected in series and supposed to be fed from a battery via an inverter. One motor is responsible of driving the front right wheel and the other of driving the front left wheel. An integral battery charger for Four-Wheel drive electric vehicle [11] is proposed which fully uses the hardware of the four-wheel drive electric vehicle. It has no extra component except a mechanical transfer switch. The inverters and the traction motors for the propulsion of the vehicle are transformed to a battery charger. It is verified by a prototype experiment that the charger can be operated at unity power factor and can match any kind of charging mode, such as constant voltage or constant current. An investigation of electric vehicle implemented by two series dc series motors is proposed [12]. The differential gear box should be used when one driving motor is used. To avoid using this differential gear box and its mechanical coupling system with wheels, two electric motors are used, where the first motor is simply coupled to the right wheel, while the second one is coupled to the left wheel. These two wheels could be the back or front wheels.

\section{System description, operation and analysis}

The major components of the system are represented in Fig. 1, the two induction motors have 1/6 HP each and the parameters are given in the Appendix, two microprocessor 8088, four mosfets of type IRFP 740, two of them (main and freewheeling) are used to control the input voltage to the first motor attached to the left whoel, while the 
other two mosfets (main and freewheeling) are connected to the second motor attached to the right wheel and used to control the input voltage to the second motor. The mosfet pulses are controlled by a microprocessor port through a driver circuit as shown in Fig.2, according to a Bang-Bang control technique algorithm written in an assembly language and stored in an EPROM interface with a microprocessor. There are two error signals, first of them (error 1 ) is between the reference right speed $\left(\operatorname{Ref}_{1}\right.$ ) and speed of the right motor $\left(\mathrm{N}_{1}\right)$, but second error (error 2 ) is between the reference left speed (Ref $)_{2}$ and speed of the left motor $\left(\mathrm{N}_{2}\right)$. The Mosfets pulses are synchronized with the supply voltage using a synchronized circuit as shown in Fig.3. The proposed system is excited from the main supply through a single phase cable with a suitable length. In the straight motion, the speed of both right and left wheels will be the same (Ref.1=Ref.2 ), but in curved motion, one wheel will be faster than the other. Thus, one motor will be faster than the other. So, adjusting Ref.1 and Ref. 2 will achieve the desired speed of both two motors.

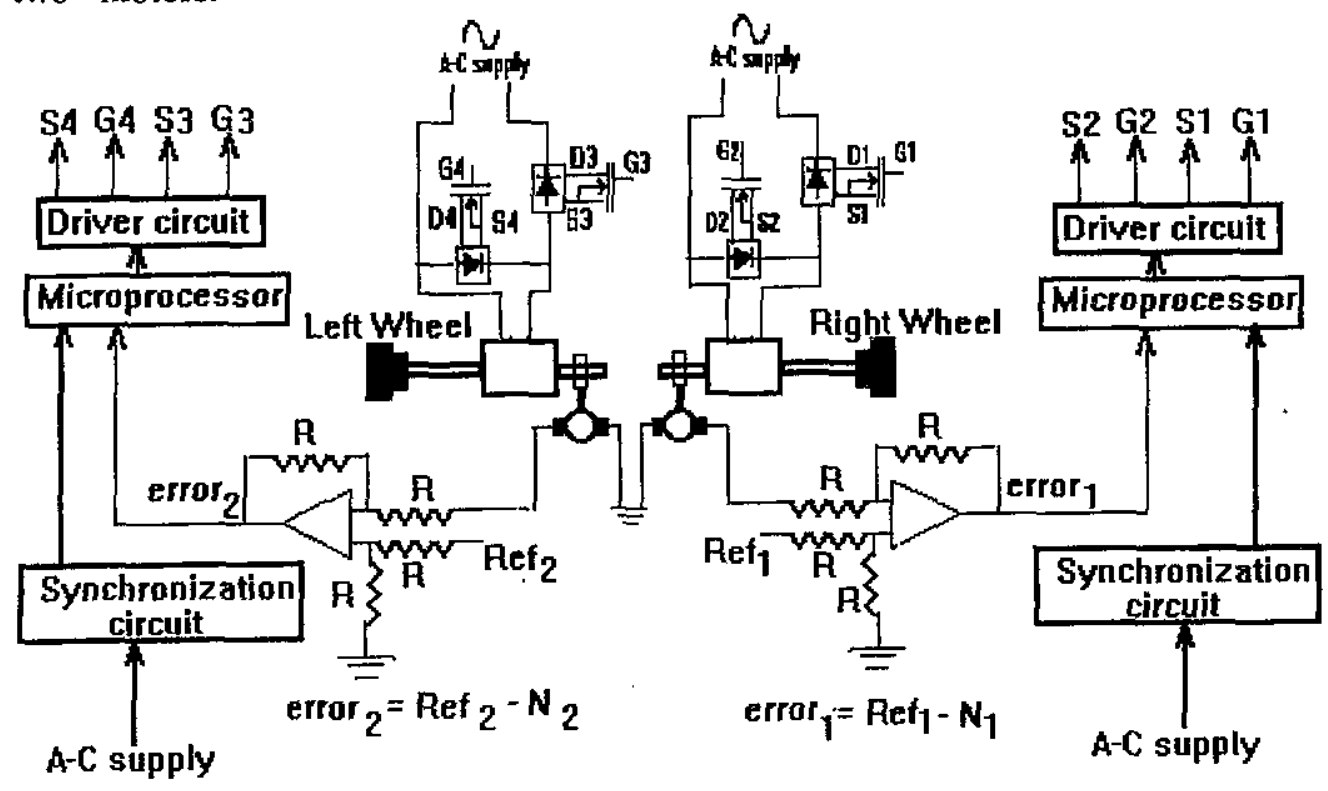

Fig. 1 An experimental simulator for the proposed System 


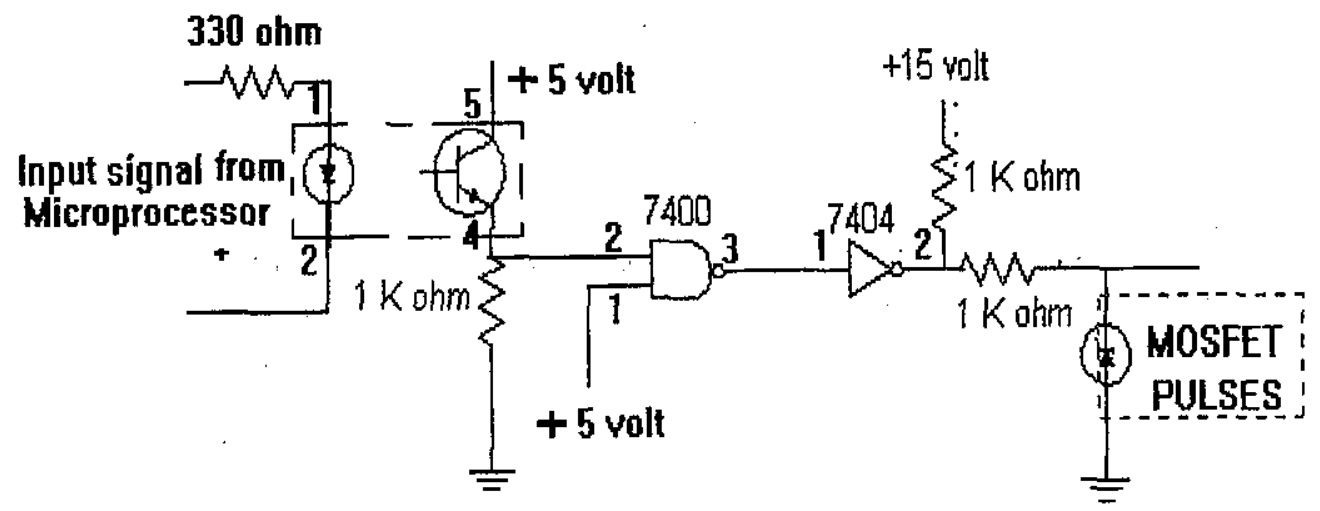

Fig. 2 Driver circuit for MOSFET

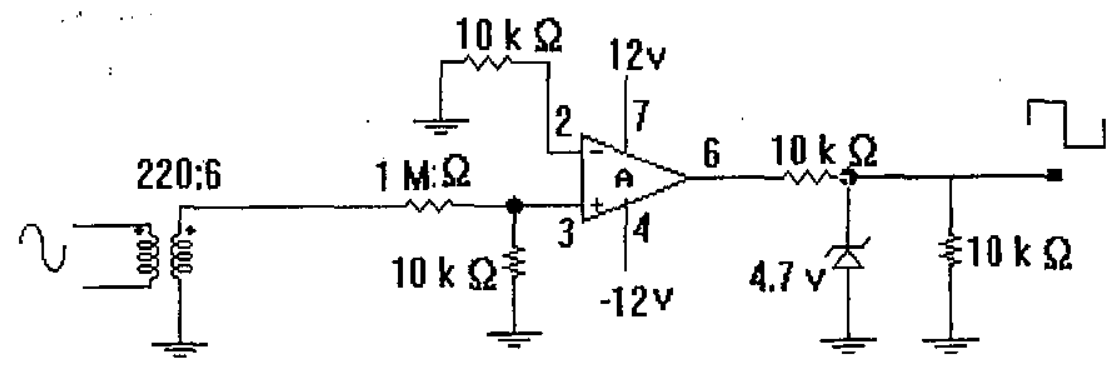

Fig. 3 Synchronization circuit

\section{2-1 Motor controlling technique}

Comparing between left reference speed $\left(\operatorname{Ref}_{1}\right.$.) and the left motor speed (tacho-generator feed back signal - $\mathrm{N}_{1}$ ) through summing circuit used to give the error signal, $A / D$ circuit transfers the error signal to the microprocessor for arranging the MOSFETs switching. Applying bang-bang control action [6] as follows ; if error $>$ zero hence turn on MOSFET 1 and turn off MOSFET 2, otherwise if error $1 \leq$ zero hence turn off MOSFET 1 and turn on MOSFET 2. The same rules are applied to the right motor, comparing between right reference speed $\left(\operatorname{Ref}_{2}\right.$.) and the right motor speed (tachogenerator feed back signal- $\mathrm{N}_{2}$ ) through summing circuit used to give the error signal, A/D circuil transfers the error signal to the microprocessor for arranging the MOSFETs switching. Applying bang-bang control action as follows ; if error $2>$ zero hence turn on MOSFET 3 and turn off MOSFET 4 , otherwise if error $2 \leq$ zero hence turn off MOSFET 3 and turn on MOSFET 4. 


\section{2-2 Motor mathematical model}

Since the stator windings of single-phase induction motors are not identical, it is necessary to transform all machine variables to stationary reference frame in order to obtain voltage equations with constant parameters. Neglecting core losses, saturation, and assuming that the mutual inductance between stator and rotor winding varies according to a simple cosine law [8]. The state equations for running a capacitor single phase induction motor, and the motor equations in $\mathrm{d}-\mathrm{q}$ axis (Fig. 4) can be written as follows: [9]

$V_{m}=\left(R_{m}+L_{m} \rho\right) i_{m}+M \rho i_{\alpha}$

$V_{m}-V_{c}=\left(R_{a}+L_{a} \rho\right) i_{a}+A_{S} M \rho i \beta$

$0=M \rho i^{-}-A_{S} M \frac{d \theta}{d t} i_{a}+\left(R_{r}+L_{r} \rho\right) i_{\alpha}-L_{r} \frac{d \theta}{d t} i_{\beta}$

$0=M \frac{d \theta}{d t} i_{m}+A_{S} M \rho i_{a}+L_{r} \frac{d \theta}{d t} i_{\alpha}+\left(R_{r}+L_{r} \rho\right) i \beta$

where $\quad v_{c}=\frac{1}{c} \int i_{a} d t$

The instantaneous electromagnetic torque may be expressed in terms of substitute variables as:

$\mathrm{T}_{\mathrm{e}}=\mathrm{P} M\left(\mathrm{i} \quad \mathrm{i}_{\mathrm{m}}-\mathrm{I} \quad \mathrm{i}_{\mathrm{a}} \mathrm{A}_{\mathrm{s}}\right)$

and the equation representing the mechanical behavior of the motor can be written as follows:

$\mathrm{J} \frac{\mathrm{d} \omega_{\mathrm{r}}}{\mathrm{dt}}=\mathrm{T}_{\mathrm{e}}-\mathrm{T}_{\mathrm{L}}-\mathrm{K} \mathrm{r}$

There are two modes of operation:

Mode(1) For MOSFETs 1,3 ON and MOSFETs 2,4 OFF, $V_{m}=V_{s}$, Where $V_{S}$ is the supply voltage

Mode(2) For MOSFETs $1,3 \mathrm{OFF}$ and MOSFETs $2,4 \mathrm{ON}, \mathrm{V}_{\mathrm{m}}=$ zero The present model is valid for both steady-state and transient conditions. 


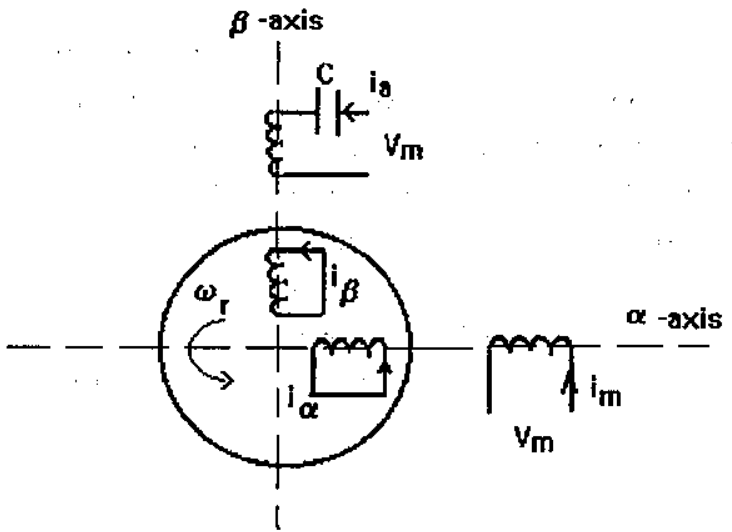

Fig. 4 Representation of single-phase induction motor

The last nonlinear differential equations of the machine are solved. The solution of these equations are obtained using the 4th order Runge-Kutta method. The instantaneous and steady state performance of motor (speed and current) are obtained from the numerical simulation.

\section{System performance and experimental results}

A prototype of the proposed system is built in the Laboratory and is tested in different cases of operation to study the motor performance. A simulation study is carried out with respect to the motor equations, control equations and solving both of them using the Fourth-order Rung-Kutta technique with a suitable interval of $100 \mathrm{sec}$. and using a FORTRAN program to do that. For a certain reference speed of 400 r.p.m, Figs.5-6 show cases study of an experimental and simulation results of speed for both motors at different conditions of references speed (ref.1 and ref.2) at steady state and supply input voltage $=110$ volt.. From these figures, a motor speed follows a corresponding reference speed and a good accuracy is obtained between experimental and simulation results. Figure 7 shows the experimental results of motor terminal and current at low speed of motor $=382.36$ r.p.m. and 208.56 r.p.m. Also, a simulation results in Fig.8 verifies the simulation results of Fig.7. The result indicates a good accuracy of a zero crossing determined by a microprocessor program, and hence an appropriate pulses to Mosfets depending upon Bang-Bang control algorithm to achieve a required motor speed. Also a good agreement between experimental and simulation results is obtained.

Figure 10 shows the experimental and simulation results of the supply current to each motors at different references values, a good agreement between the experimental and simulation results is 
achieved at reference speed of motor $1=556.16$ r.p.m. and the reference speed of motor $2=208.56$ r.p.m. Figure 11 shows the experimental response of the motor speed during change in the reference speed during the startup period and the steady state interval. It is noticed that the motor response follows the reference speed. This means that - the proposed controller is accurate and smooth during the period of change. Figure 12 show motor speed when supply voltage is stepped down by $20 \%$ of its rated value. Figure 13 shows the experimental of motor response when the load torque is stepped up by $20 \%$ of full load torque. A good agreement between experimental and simulation results is obtained. Ripple in the experimental speed response due to the tacho-generator used, these ripple can be minimized by using a suitable capacitor :(10 f $)$ across the tacho-generator terminals.

\section{Conclusion}

A proposed proto-type of ac drive system operating on-line. It is composed of two single phase induction motor for use in special electric vehicle used in big factories to transport objects between places with radial or curvature trajectory. The first motor is simply coupled to right wheel, while the second one is coupled to left wheel. In straight motion, both motors speed are the same, but in curvature motion, one wheel will be faster than the other. Thus one motor will be faster than the other. An experimental simulator of the proposed system is implemented. The simulation results agree with the experimental results. From these results, it is clear that the proposed system is suitable for a special vehicle giving accurate and efficient control, suitable for radial or curved trajectory electrical traction with minimum electronic switches.

\section{References}

[1] Hussein F. Soliman, M.A.L.Badr, and A.M.Sharaf, "A fuzzy logic controller for a dc series motor chopper fed locomotivedrive", ICECS'97, December 15-18, 1997, Cairo, Egypt, pp. 592-597.

[2] Dietrich Naunin, "Electric Vehicles". ISIE'96, June 17-20, 1996, Warsaw, Poland.

[3] Brian J. Chalmers, Lawrence Musaba, and David F. Gosden, "Variable-frequency synchronous motor drives for electric vehicles". IEEE Tran. on Ind. applic., Vol. 32, No. 4, 1996.

[4] A.H. Haddon, M.Kadjoudj, R.Abdessemed, and C.Chennai, "Modeling of electric vehicle system", 33 rd. Universities Power Eng. Con., Edinowign, un. Sep. 8-10, 1998. 
[5] Bimal K. bose, "A microprocessor-based control system for a near-term electric vehicle", IEEE Tran. on Ind. application, vol. IA-17, No.6, Nov. 1981.

[6] Awad El-sabbe and Ashraf Zein El-Din, "Speed control of a single phase ac motor by using ac voltage regulator ", MEPCON' 98, El-Mansoura-Egypt, 14-16 December 1998

[7] A.Benoudit, N.Nait Said, M.Kadjoudj, and M. bentayeb, "Simulation of an electronic differential for an electric propulsion system", UPEC'98, pp. 428-431.

[8] [8]S.S.Shokralla and A.M.Kinawy, "Perturbation analysis of a single-phase capacitor induction motor in time and frequency domains", Menoufia University, Faculty of Engineering, Eng. Research Bull., vol.16, Part.2, 1993, pp.179-201

[9] A.S.Zein El-Din and A .E. El-Sabbe and S.A.Mahmoud, "A novel ac voltage regulator", IECON98, 24 th Annual conference of the IEEE Industrial Electronics Society, Aachen-Germany, Volume 2/4, August 31-September 4, 1998, pp. 607-611

[10] S.A.Eldhemy and G.Ghoneem, "An electric vehicle driven by two similar solid rotor induction motors", MEPCON'97, Alexandria, Egypt, Jan. 4-6, 1997, pp.116-125.

[11] [11]Seung-ki Sul, and sang-Joon Lee, "An integral battery charger for four-wheel drive electric vehicle", IEEE Trans. on Industry applications, vol. 31, No. 5, September/October 1995, pp. 1096-1099

[12] Mohsen Z. El-Sherif, "Investigation of electric vehicle implemented by two series de series motors", Electromotion' 99 , Patras, Greece, 1999, pp.847-852

\section{6- Appendix}

Each of the two 1/6 HP single phase running capacitor induction motors has :

220 volt. rated voltage., $50 \mathrm{~Hz}, 1.2$ amp rated current and 1325 r.p.m. rated speed, $\mathrm{Ls}=\mathrm{Lr}=0.715 \mathrm{H}, \mathrm{Rr}=15.1, \mathrm{R}_{\mathrm{S}}=15.1$, $\mathrm{M}=0.2 \mathrm{H}, \mathrm{C}=7 \quad \mathrm{~F}$, and $\mathrm{As}=1$.

In other case, load (motor) parameters are $\mathrm{Ls}=\mathrm{Lr}=36.5 \mathrm{~m} . \mathrm{H}, \mathrm{Rr}=$ Rs $=8$. 


\section{7- Symbols}

$\mathrm{A}_{\mathbf{S}}$ : Auxiliary to main winding turns ratio.

C: Auxiliary winding capacitance

D1, S1, G1: Drain, source and gate of mosfet 1

D2, S2, G2: Drain, source and gate of mosfet 2

D3, S3, G3: Drain, source and gate of mosfet 3

D4, S4, G4: Drain, source and gate of mosfet 4

$\mathrm{i}_{\mathrm{a}}, \mathrm{i}_{\mathrm{m}}$ : Auxiliary and main winding current.

$\mathrm{i}, \mathrm{i}$ : rotor current.in and axis;

$\mathrm{J}$ : Moment of inertia in Kg.m ${ }^{2}$

$\mathrm{L}_{\mathrm{a}}, \mathrm{L}_{\mathrm{m}}, \mathrm{L}_{\mathrm{r}}$ : Auxiliary, main and rotor winding self inductance.

M: Main to rotor mutual inductance.

N1: Right motor speed.

N2: Left motor speed.

$\mathrm{K}$ : Friction constant.

P: number of pole pairs.

: d/dt

$R_{a}, R_{m}, R_{r}$ : Auxiliary, main and rotor winding resistance.

Ref1: Reference speed of right motor.

Ref2: Reference speed of left motor.

Te: Electromagnetic developed torque.

$\mathrm{T}_{\mathrm{L}}$ : Load torque.

Vs : Supply voltage

Vc: capacitor terminal voltage .

$\mathrm{V}_{\mathrm{m}}$ :Amplitude of a.c. Input voltage

$V_{m 1}$ : motor one terminal voltage

$\mathrm{V}_{\mathrm{m} 2}$ : motor two terminal voltage

: Electrical angle between stator and rotor.

$\mathrm{r}$ : Motor speed in $\mathrm{rad} . / \mathrm{sec}=\mathrm{d} / \mathrm{dt}$ 


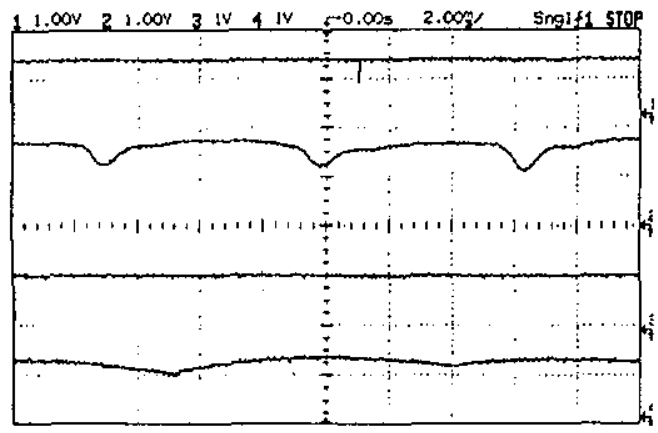

Ch.l Refl $=382.36$ r.p.m. Ch.2 Motor speed 1 Ch.3 Ref2 $=382.36$ r.p.m. Ch.4 Motor speed 2 (a)
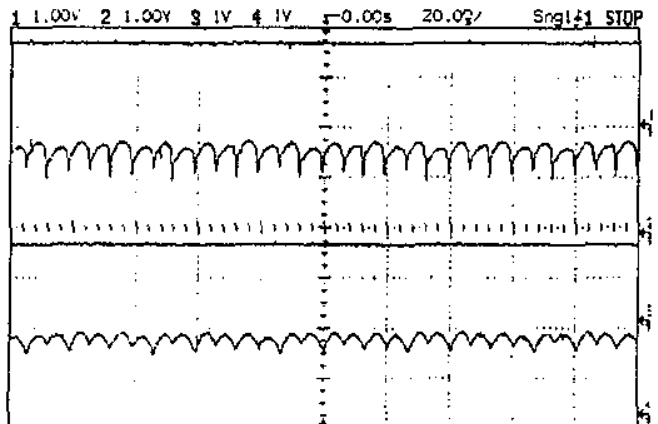

Ch. 1 Ref $1=556.16$ r.p.m. Ch.2 Ref2 $=556.16$ r.p.m.

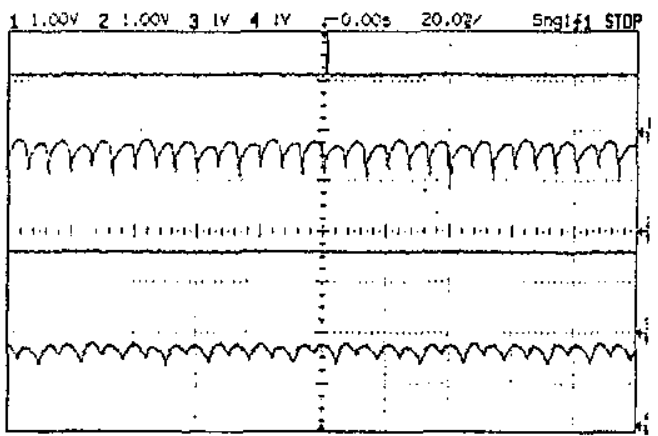

Ch. 1 Refl $=382.36$ r.p.m. Ch.2 Ref2 $=556.16$ r.p.m. (b)

Ch.2 Motor speed I Ch. 4 Motor speed 2

Ch.2 Motor speed 1 Ch. 4 Motor speed 2

(c)

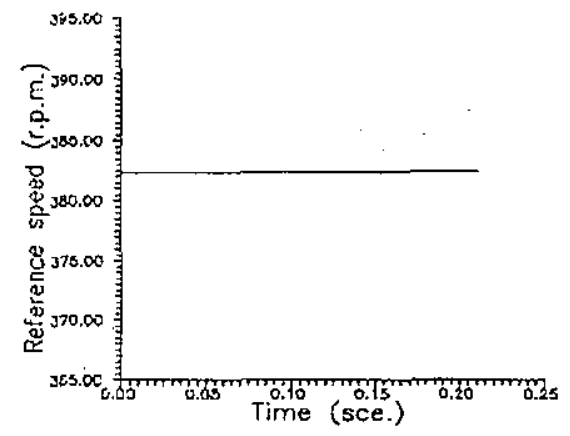

(a)

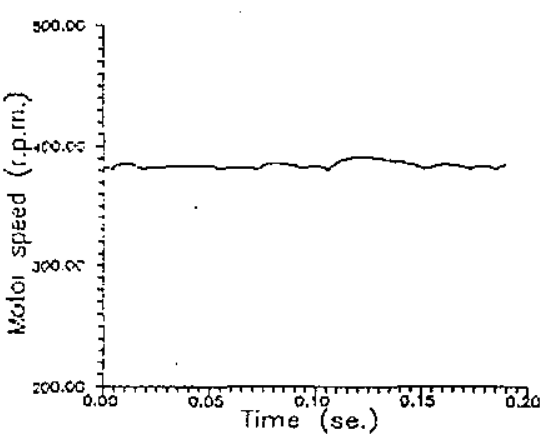

(b)

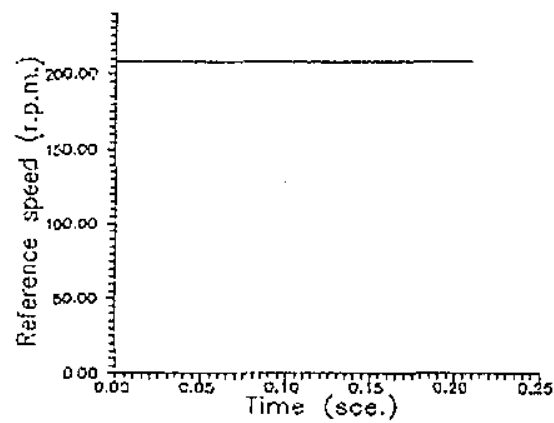

(c)

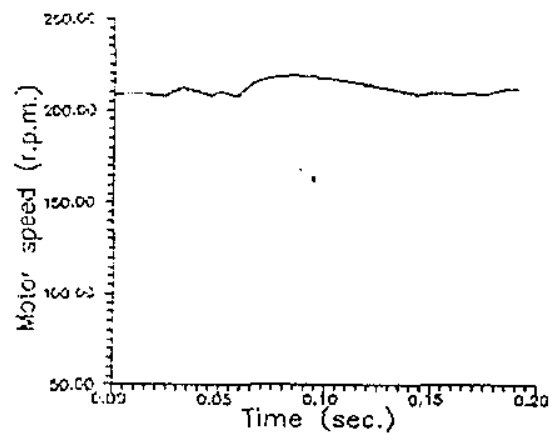

(d) 


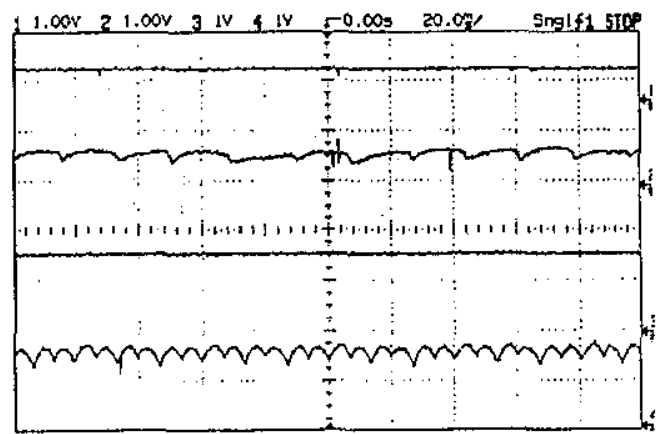

Ch. $|\operatorname{Ref}|=208.56$ r.p.m. Ch.2 Ref2 $=556.16$ r.p.m.

(d)

Ch. 2 Motor speed 1 Ch. 4 Motor speed 2

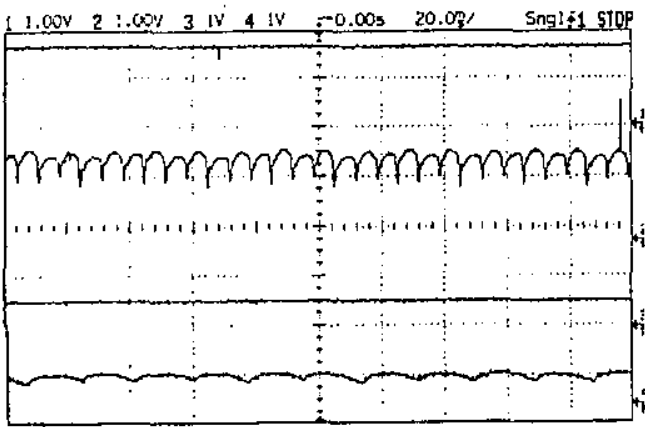

Ch. 1 Refl $=556.16$ r.p.m. Cl. 2 Ref $2=208.56$ r.p.m.

Ch.2 Motor speed I Ch.4 Motor speed 2 (e)

Fig. 5 Experimental results of motors speed at different cases of references values

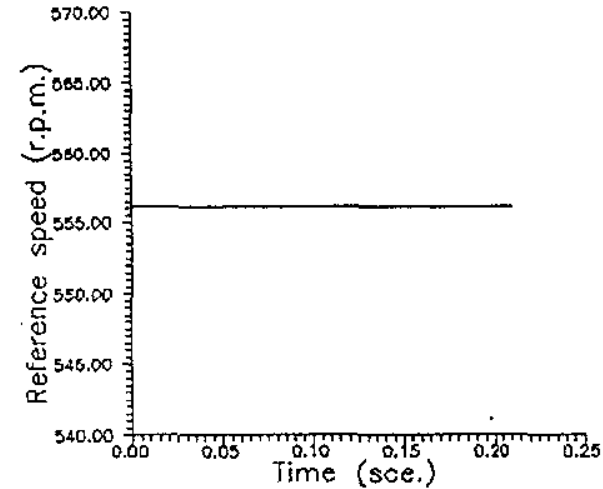

(f)

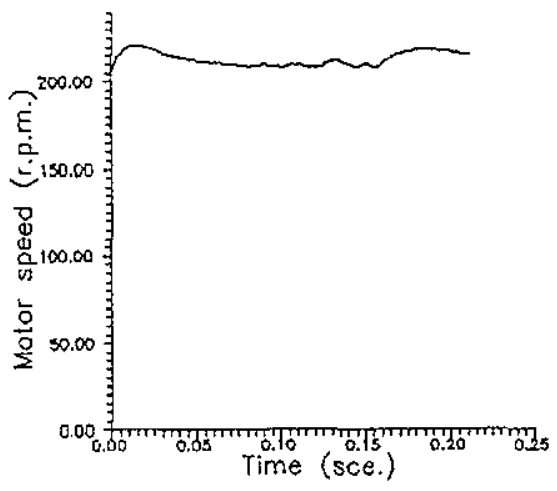

(g)

Fig. 6 Simulation results of motors speed at different cases of references values 


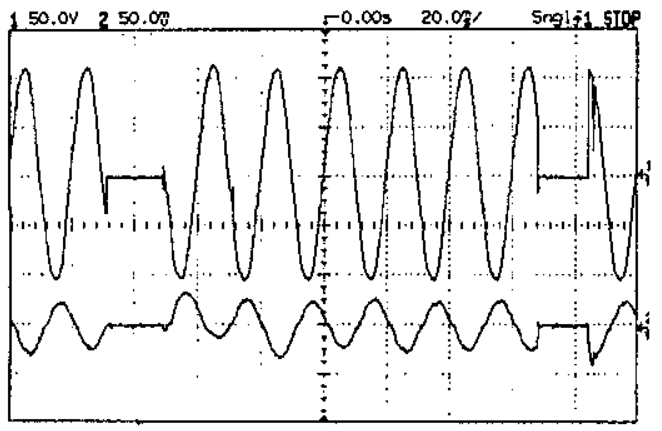

Ch.1 Motor terninal voltage Ch.2 Motor current

(a)
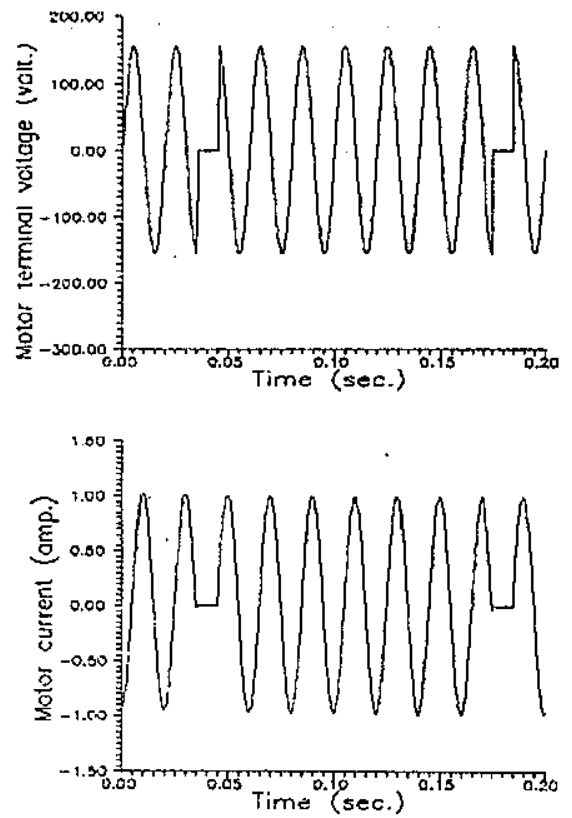

(a)
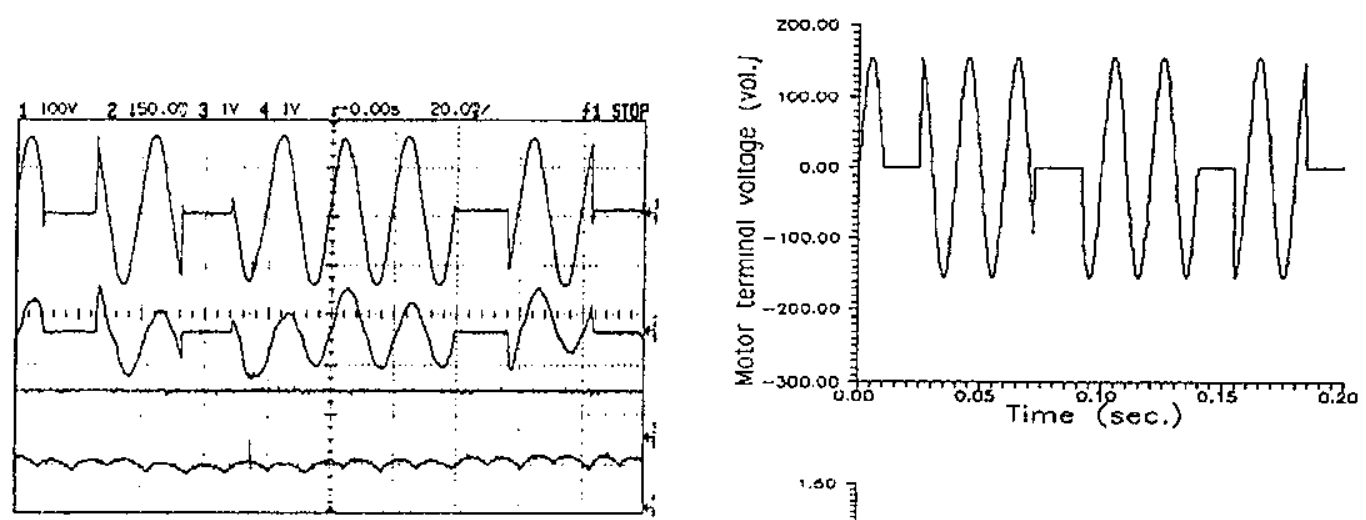

Ch.1 Motor terminal voltage Ch.2 Motor current Ch.3 Reference speed

(b)

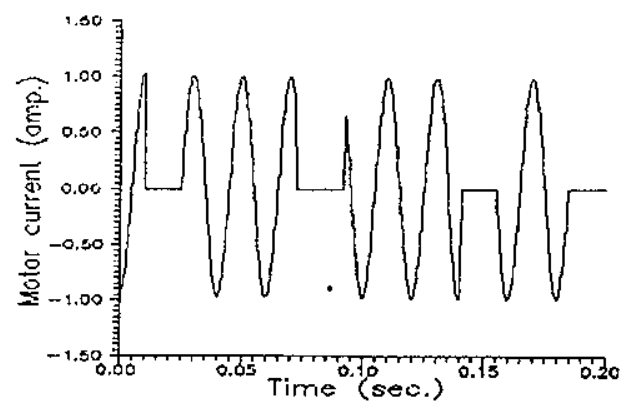

(b)

Fig. 8 Simulation results of motor performance at (a) Reference speed $=382.36$ r.p.m. (b) Reference speed $=208.56$ r.p.m. 


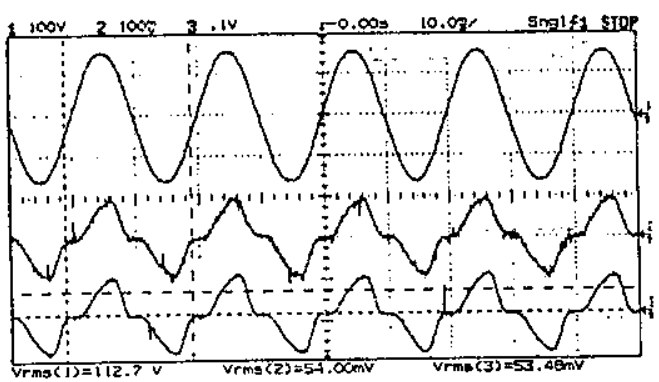

Ch.1 Supply voltage

Ch.2 Supply current to motor 1 at Ref. $1=556.1$ r.p.m. Ch. 3 Supply current to motor 2 at Ref.2=556.1 r.p.m.

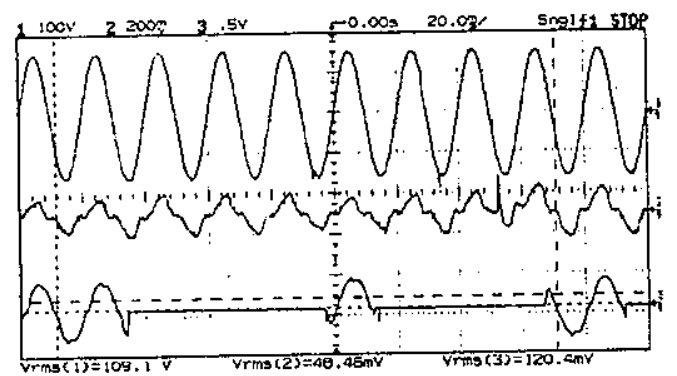

Ch.l Supply voltage

Ch.2 Supply current to motor 1 at Ref. $1=556.1$ r.p.m.

Ch. 3 Supply current to motor 2 at Ref.2=208.5 r.p.m.

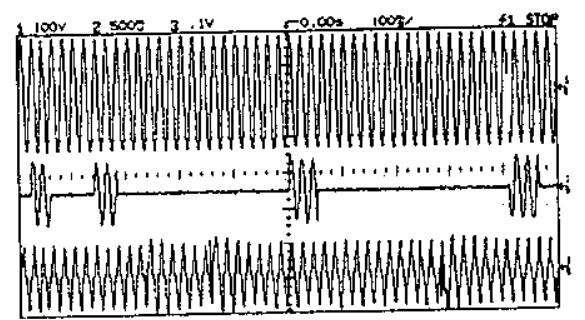

Ch.I Supply voltage

Ch.2 Supply current to motor 1 at Ref. $1=208.5$ r.p.m. Ch. 3 Supply current to motor 2 at Ref. $1=556: 1$ r.p.m.

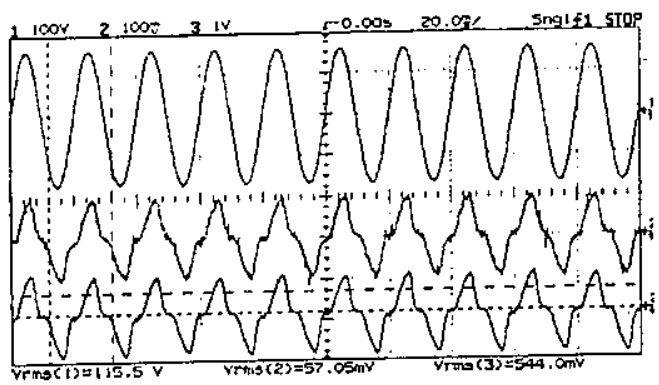

Ch.1 Supply voltage

Ch.2 Supply current to motor 1 at Ref. $1=382.3$ r.p.m.

Ch.3 Supply current to motor 2 at Ref.2=556.1 r.p.m.

Fig. 9 Experimental results of supply current to motor 1 and motor 2 at different reference speed.

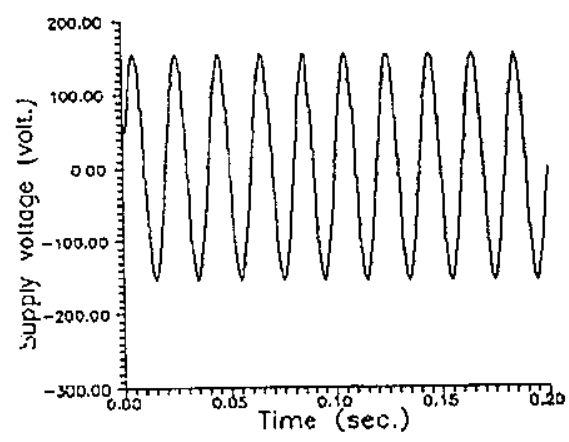

(a)

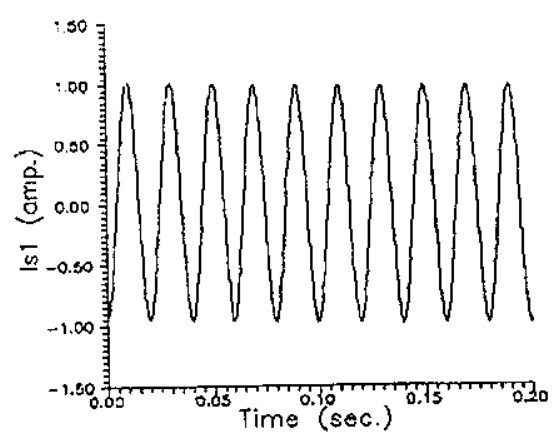

(b)

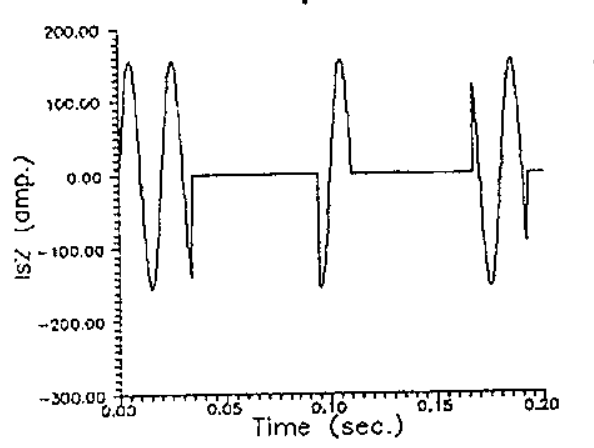

(c)

Fig. 10 Simulation result of

(a) Supply voltage

(b) Supply current to motor 1 at Ref. $I=556.16$ r.p.m.

(c) Supply current to motor 2 at. Ref. $2=208.56$ r.p.m. 


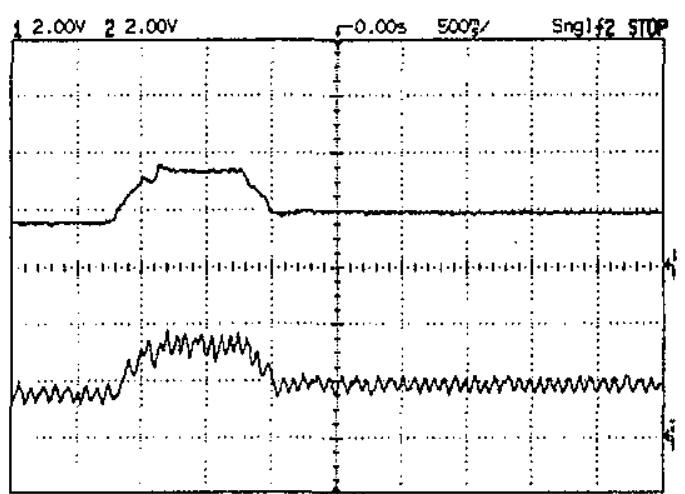

Ch.l Motor reference speed

Ch.2 Motor speed

Fig. 11 Transient response of motor speed (Experimental result)

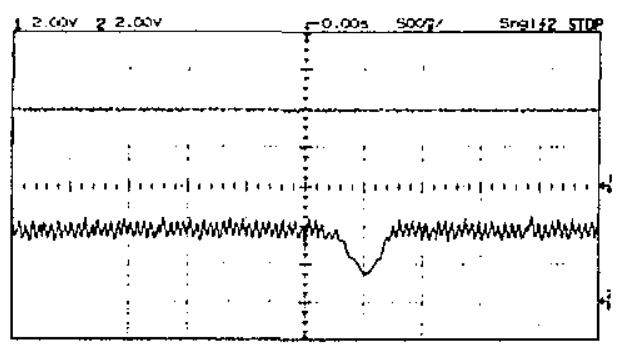

Ch.l Motor reference speed

Ch.2 Motor speed

Fig. 12 Experimental result if supply voltage is stepped down by $20 \%$

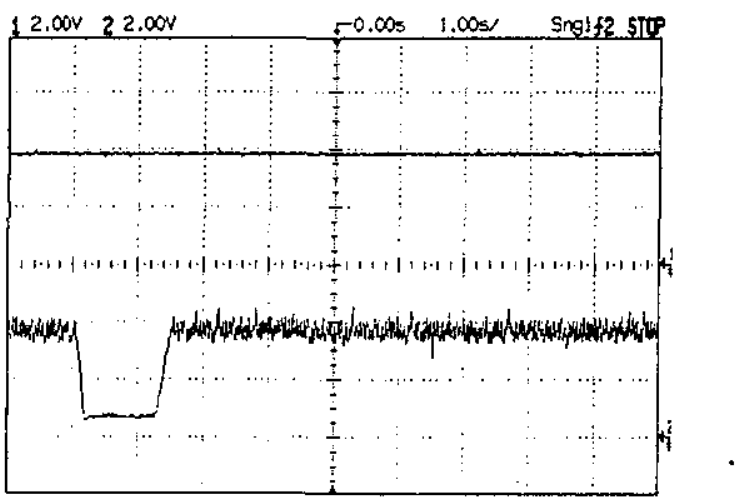

Ch.l Motor reference speed

Ch. 2 Motor speed

Fig. 13 Experimental resul if load torque is stepped up by $20 \%$ 


\section{نو عية جديدة لعربات النقل الكهربى}

\section{د.مصطفى السيد الشبينى}

أستاذ مساعد بقسم الهندسة الكهربية - كلية الهندسة بشبين الكوم

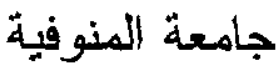

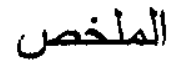

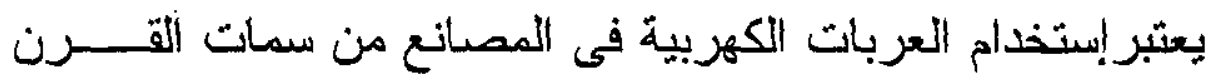

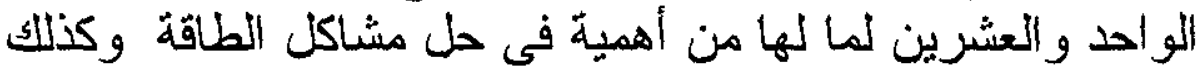

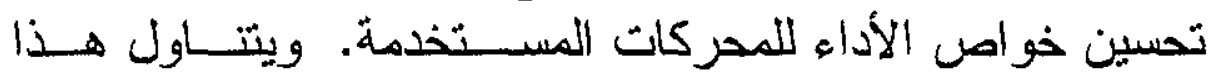

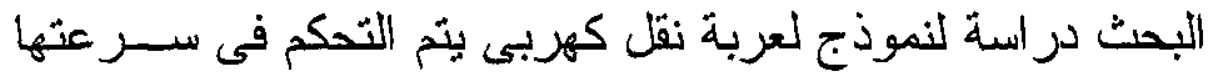

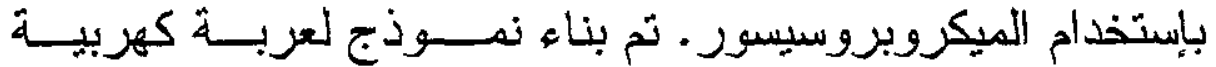

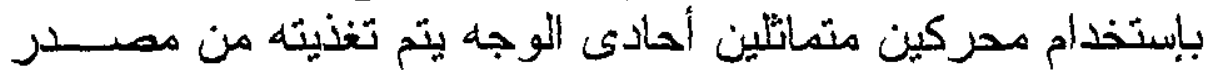

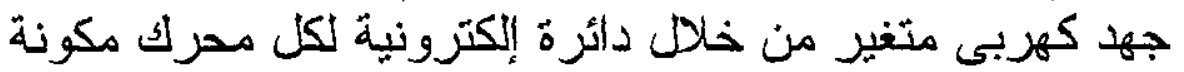

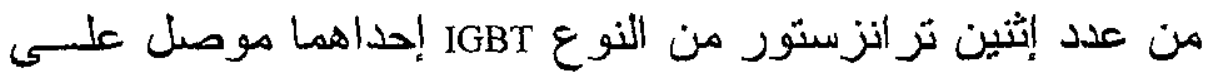

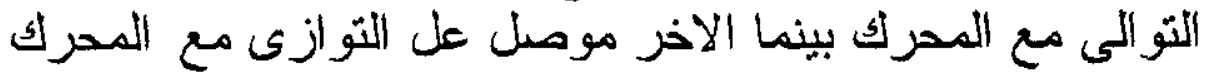

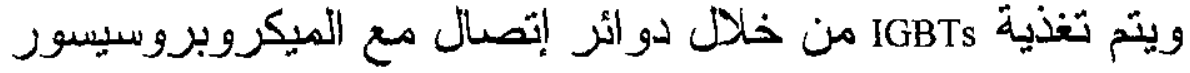

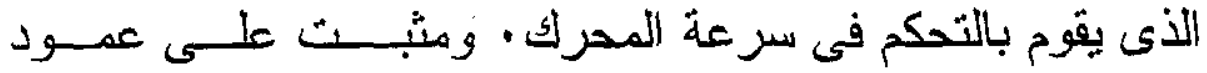

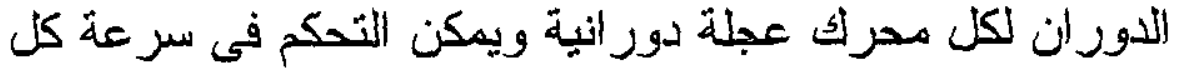

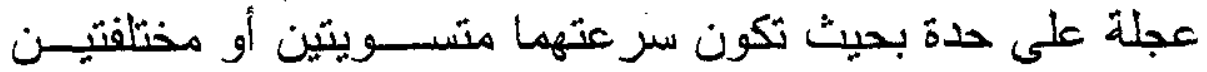

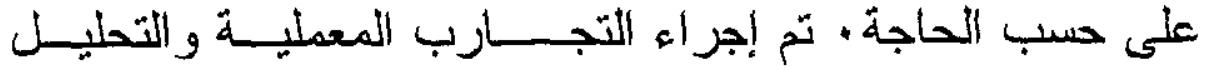

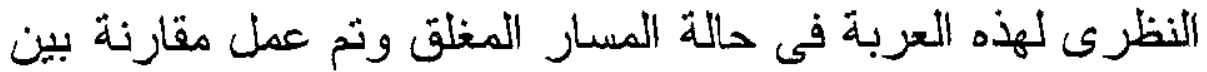

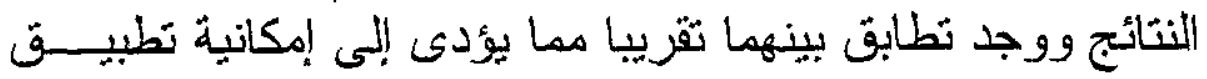

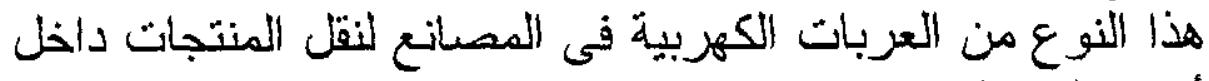

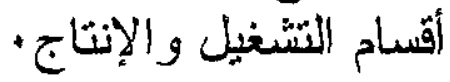

